\title{
Corrosion Inhibition Effect of Molybdate on Fine-Grain High- Strength Reinforcement in Simulated Concrete Pore Solutions Containing $\mathrm{Cl}^{-}$
}

\author{
Bilan $\operatorname{Lin}^{1,2, *}$ and Yuye $X u^{3}$ \\ ${ }^{1}$ School of Material Science and Engineering, Xiamen University of Technology, Xiamen 361024, \\ China \\ ${ }^{2}$ Key Laboratory of Functional Materials and Applications of Fujian Province, Xiamen 361024, China \\ ${ }^{3}$ College of Civil Engineering, Huaqiao University, Xiamen, Fujian 361021, China \\ *E-mail: $\underline{\text { linbilan@xmut.edu.cn }}$
}

doi: $10.20964 / 2019.01 .52$

Received: 10 October 2018 / Accepted: 31 October 2018 / Published: 30 November 2018

To improve the corrosion resistance of fine-grain high-strength (FGHS) reinforcement, molybdate was investigated as a inhibitor. The influence of molybdate on the corrosion behavior of FGHS reinforcement in simulated concrete pore (SCP) solutions containing $1.0 \%$ or $3.5 \% \mathrm{NaCl}$ was evaluated using polarization, electrochemical impedance spectroscopy, and Mott-Schottky curves. The corrosion products were analyzed using scanning electron microscopy and energy-dispersive X-ray spectroscopy. The results revealed that upon increasing the molybdate content, the corrosion current density $\left(i_{\text {corr }}\right)$ and donor density initially rapidly decreased and then slightly increased, while the corrosion protection efficiency and impedance first rapidly increased and then slightly decreased. The optimum molybdate was $1.0 \mathrm{~g} / \mathrm{L}$. The $i_{\text {corr }}$ of the former $\left(0.058 \mu \mathrm{A} \mathrm{cm}{ }^{-2}\right)$ was considerably less than that of the latter $\left(0.250 \mu \mathrm{A} \mathrm{cm}^{-2}\right)$. The Mott-Schottky curves for the former were continuous, whereas some of those for the latter were discontinuous owing to the depletion of a less $\mathrm{Fe}^{3+}$ in the corrosion product. Almost no pits on the reinforcement were observed for the former, whereas a few pits were still observed for the latter. Molybdate exhibited good corrosion inhibition of FGHS reinforcement at low chloride concentrations, although other or composite inhibitors should be considered for high chloride concentrations.

Keywords: Reinforcement; Fine grain; Corrosion; Inhibitor; Molybdate

\section{$\underline{\text { FULL TEXT }}$}

(C) 2019 The Authors. Published by ESG (www.electrochemsci.org). This article is an open access article distributed under the terms and conditions of the Creative Commons Attribution license (http://creativecommons.org/licenses/by/4.0/). 